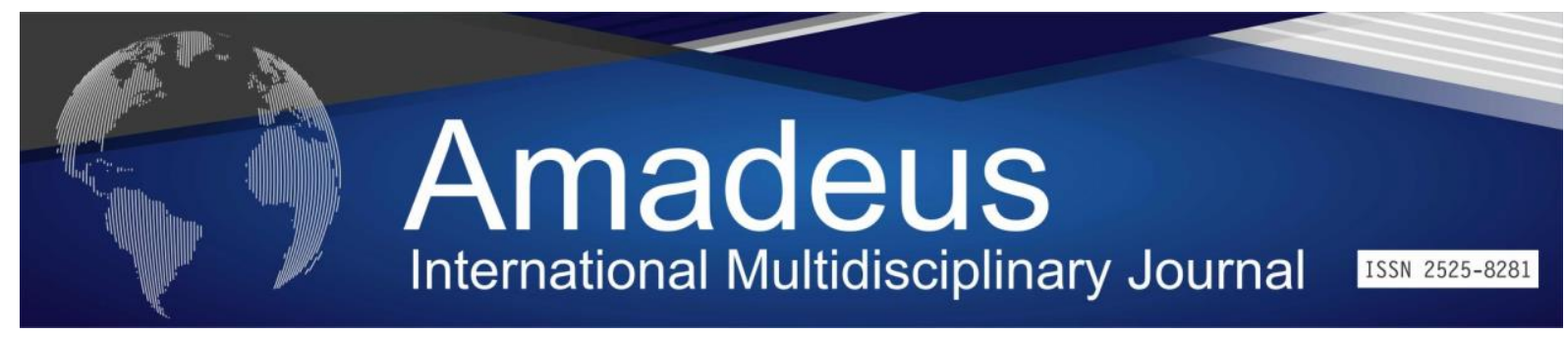

DOI: 10.14295/aimj.v5i9.144

\title{
Curriculum and Identity its Impacts on the School Context in Goiás: Points and Counterpoints
}

\section{Marcelo Máximo \\ Purificação ${ }^{l}$ \\ Elisângela Maura Catarino ${ }^{2}$ \\ Maria Filomena Rodrigues \\ Teixeira ${ }^{3}$ \\ Lousana de Jesus Santana ${ }^{4}$ \\ Cláudia de Souza Abdalla \\ Angélica Ferreira Alves ${ }^{6}$}

Abstract: One of the biggest challenges of contemporary education is to work with diversity, and identity plurality in school spaces, spaces in which relationships are often marked by tensions, conflicts, due to the asymmetries of power that permeate them and cause the construction of hierarchy, processes of subordination, (re) affirm prejudices, discrimination and violence in relation to certain social actors. It is a text of bibliographic review, in a qualitative approach, approaching the theoretical aspect of Cultural Studies.

Keywords: Culture. Curriculum. Differences. Cultural Studies.

\section{Currículo e Identidade seus Impactos no Contexto Escolar em Goiás: Pontos e Contrapontos}

Resumo: Um dos maiores desafios da educação contemporânea é trabalhar a diversidade e a pluralidade identitária nos espaços escolares, espaços esses em que as relações estão muitas vezes marcadas por tensões, conflitos, em função das assimetrias de poder que as permeiam e provocam a construção de hierarquia, processos de subalternização, (re) afirmam preconceitos, discriminações e violências em relação a determinados atores sociais. É um texto de revisão bibliográfica, numa abordagem qualitativa, aproximando-se do aparo teórico dos Estudos Culturais.

Palavras-chave: Cultura. Currículo. Diferenças. Estudos Culturais.

\footnotetext{
${ }^{1}$ Pós-Doutor em Educação - pela Faculdade de Psicologia e Ciências da Educação da Universidade de Coimbra (FPCE/UC). Doutor em Ciências da Religião (PUC-GO, 2014). Doutorando em Ensino (UNIVATES). Doutorando em Educação (ULBRA). Professor Permanente do nos Programas de Pós-Graduação em Educação (FACMAIS) e (UEMS-Cooperação Técnica) e no MPIES/UNEB (Cooperação Técnica).Professor Titular C-II na UNIFIMES. E-mail: maximo@unifimes.edu.br;

${ }^{2}$ Doutora em Ciências da Religião pela Pontifícia Universidade Católica de Goiás (PUC-Goiás), Doutoranda em Educação pela Universidade Luterana do Brasil (ULBRA). Mestra em Educação Comunitária pela Faculdades EST/UFRGS. Professora Titular na Fundação Integrada Municipal de Ensino Superior-FIMES/UNIFIMES. E-mail: maura@unifimes.edu.br;

${ }^{3}$ Doutora em Didática pela Universidade de Aveiro - Portugal. Coordenadora e Professora Adjunta da Escola Superior de Educação de Coimbra -ESEC. E-mail: filomena.tx@gmail.com;

${ }^{4}$ Graduada em Pedagogia e aluna regular do Mestrado Profissional em Intervenção Educativa e Social (MPIES) Linha 2: Novas formas de subjetivação e organização comunitária, na Universidade do Estado da Bahia (UNEB), Departamento de Educação (DEDC) do Campus XI - Serrinha-Ba. E-mail: lousanasantana@gmail.com;

${ }^{5}$ Graduada em Pedagogia pela Universidade Estadual de Goiás (UEG). Mestranda em Educação, no Programa de Pós-graduação em Educação da Faculdade de Inhumas - FACMAIS. E-mail: claudia@ facmais.edu.br;

${ }^{6}$ Graduada em Educação Musical pela Universidade Federal de São Carlos (UFSCar/SP). Licenciada em Letras pela (UNIJALES/SP). Mestranda em Educação pela Universidade Estadual de Mato Grosso do Sul (UEMS/Paranaíba) E-mail: angelicalima09@ hotmail.com.
} 


\section{Introdução}

Este texto remete-se às primeiras leituras e discussões no âmbito do Projeto de Pesquisa intitulado: "Processos Educativos - a formação de professores e as dimensões do currículo dialogando com as diferenças um estudo das diretrizes curriculares da SEDUCE/Goiás e seus impactos no contexto escolar" cadastrado na Diretoria de Pesquisa e no Núcleo de Estudos, Pesquisa e Extensão Multidisciplinar - NEPEM/CNPq do Centro Universitário de Mineiros/UNIFIMES.

Os processos pedagógicos que se desenvolvem nos espaços escolares, ou em função deles, são fundamentais para se pensar, fundamentar e estruturar a dimensão da educação como processo de formação humana. A sociedade brasileira e, em particular, a da região onde se desenvolvem os estudos, é marcada por diferentes culturas, em que se expressam aspectos e características particulares e peculiares, envolvendo fatores étnicos, sociais, religiosos, etc., dos grupos que a compõem. Nessa sociedade, é importante compreender os contextos nos quais os grupos socializam os mesmos pensamentos e desenvolvem manifestações culturais em comum, a exemplo da escola.

Desde a antiguidade, a escola colaborou no processo de homogeneização dos indivíduos, o que torna as relações de poder tão fortes em suas práticas (Ramalho, 2015). Por isso, o contexto escolar foi e sempre será objeto de estudos e investigações, haja vista a aproximação da escola aos problemas sociais. Na atualidade, o número dos teóricos que defendem os estudos das múltiplas culturas e identidades presentes nessas instituições vai além da área da sociologia da educação.

O discurso multiculturalista é, ainda, bastante forte no senso comum e na área da Educação. Na linha dessas ideias, podemos citar Candau (2014), quando afirma que as diferenças são componentes fundamentais das relações sociais, pois permeiam o nosso cotidiano, tanto no que se refere às relações interpessoais quanto entre os diversos grupos e movimentos presentes na sociedade. No entanto, essas relações estão muitas vezes marcadas por tensões, conflitos, em função das assimetrias de poder que as permeiam e provocam não só a construção de hierarquia, processos de subalternização como também (re)afirmam preconceitos, discriminações e violência em relação a determinados atores sociais (Candau, 2014, 23-24).

Vários poderiam ser os elementos motivadores deste estudo; no entanto, o principal está no perfil do grupo dos pesquisadores envolvidos, no qual a maioria é formada por 
professores da educação básica, alguns da educação superior e outros da pós-graduação em programas de mestrados. Eu - primeiro autor deste texto e coordenador do projeto, sou professor estável da rede estadual de educação há 27 anos, sendo 17 deles no ensino superior e, durante todo esse tempo, tenho visto muitas mudanças acontecerem no currículo escolar. Muda-se muito a dimensão do currículo e pouco se fala sobre a dimensão dos sujeitos, marcados pela diversidade cultural, social, econômica, de gênero e de identidade.

Tal concepção é validada pelos demais participantes de nosso grupo de estudo, em suas falas nas reuniões, as quais evidenciam que embora temos algumas políticas públicas que valorizam a diversidade, ainda é tímido esse diálogo nos espaços escolares e nos currículos. Por isso, desenvolver discussões, estudos e provocações que perpassem o eixo do Ensino, Formação de Professores, Identidade, Diversidade, Currículo, Ciências e Tecnologias, é primordial.

Atualmente há um consenso sobre a variedade de significações produzidas por diferentes atores do sistema educacional, quando se referem às palavras currículo e diferenças, vistas a partir da lupa teórica dos Estudos Culturais. Sobre o mesmo tema, também é possível identificar teóricos que nos aproximam do cerne dessas discussões, tais como Sacristán e Pérez, Tomaz Tadeu da Silva, Stuart Hall, Kathryn Woodeward, dentre outros. Segundo as pesquisas desses autores, para cumprir sua função social, a escola se estabelece ao longo da história como instituição modelada por estruturações formatadas tanto pelo perfil da sociedade a que servem como pela visão de sociedade que alimenta o eixo decisivo das diretrizes reguladoras do currículo, da gestão, e, consequentemente, da organização escolar. Cultiva assim, em sua essência, uma "tensão dialética" que se estabelece entre "tendências conservadoras [...] e as correntes renovadas" que habitam os contextos sociais de modo geral (Souza et al., 2013, p.110).

O desenvolvimento de uma pesquisa sobre identidades em Mineiros Goiás, vistas a partir do aparato teórico da BNCC e das Diretrizes Curriculares que regem os processos educativos é relevante para o campo da ciência, haja vista tratar-se de uma região (contextos/territórios) fortemente marcada pela presença do índio, do negro, dos migrantes nortistas, nordestinos e do sul do país. Justifica-se, ainda, pela necessidade de compreender as identidades, suas dimensões e seus impactos nos currículos, refletidos em sala de aula e nos processos de aprendizagem. Ao defender a necessidade de considerar a escola como um cenário propício e pensarmos em temas tão ligados e, ao mesmo tempo, tão díspares, encontramos respaldo em Lacasa (1994), quando propõe considerar que a escola deve ser 
entendida na relação entre os processos de mudança que nela se produzem, como um contexto essencialmente social, construído por pessoas na intersecção entre indivíduo e coletivo.

\section{O Olhar dos Teóricos sobre a Temática}

No contexto contemporâneo é acertado dizer que a educação, em todos os seus níveis, assume um papel fundamental. Nesse sentido, muitos são os estudos e pesquisas que ressaltam a função da educação e do próprio ambiente escolar nessa sociedade fortemente marcada pela pluralidade, em que a escola estabelece relação entre o sistema de ensino à problemática social.

Nessa nova fase da educação, a construção dos conhecimentos escolares ocorre no coletivo e deve dialogar com questões que contemplem a diversidade dos sujeitos presentes nos espaços escolares. Por isso, as dimensões do currículo devem perpassar temas que possam promover reflexões, tais como diferenças sociais, de gênero, de raça, de religião, o preconceito, dentre outros.

Estudos sobre a identidade e as diferenças ganham grande relevância e servem de parâmetro para reforçar a igualdade de direitos apregoada pela Constituição Federal (1988) e pela Lei de Diretrizes e Bases da Educação Nacional (Lei n 9304/96). Estudos sobre identidades como os desenvolvidos por Kreutz (1999), Strauss (2004) e Certeau (1995) nos possibilitam entender esse processo de construção identitária a partir do contexto social e, daí, compreendermos que as diferenças que marcam nossas escolas são construídas por intermédio de processos sociais singulares nascidos no seio da sociedade, que podem orientar os valores e as expectativas que geralmente orquestram as práticas (ações) pedagógicas.

Aproximando a temática identidade, diferença e poder da lupa teórica dos Estudos Culturais, constatamos que esses contextos devem ser potencializados e amplamente discutidos no âmbito educacional. As leituras e discussões feitas no desenvolvimento das ações do referido projeto de estudo/investigação, colaboraram para potencialização do conceito de diferença e seus impactos na produção da subjetividade e, a partir daí uma análise da produção de identidade e suas implicações nas relações de poder estabelecidas. Nessa perspectiva teórica, percebemos que alguns sistemas filosóficos utilizaram em sua estruturação o conceito de diferença, a exemplo de Heidegger - "diferença ontológica" - e Deleuze - "Diferença"/"repetição" - (Silveira, 2011).

Ao longo da história da criação da escola e de seu processo evolutivo, constata-se uma 
grande inclinação dessa instituição a servir aos interesses do Estado, sendo uma máquina poderosa que opera pela repetição e, nesse contexto, a produção de subjetividade que corrobora para o atendimento das demandas da máquina de produção. Nessa perspectiva, Silveira (2011), especifica que:

A escola-máquina-de-Estado está sempre preocupada com o ponto de chegada; sua função é produzir identidades, subjetividades que sejam reconhecidas como idênticas e, portanto, fechadas. Para isso, precisa estriar todo o espaço educacional e seus processos (Silveira, 2011, p. 214)

Olhando a partir do que específica Silveira (2011), percebemos a existência de um viés e centralidade sustentando as relações de poder, engendradas num fluxo ativo de capturas que, ao perpassar as subjetividades, incidem no perfil de sujeito que se deseja formar. Ainda segundo a autora, entendemos que o método em educação é, assim, um instrumento de captura.

Nessa ótica, o currículo é um elemento indispensável, pois as formas como esses sujeitos se apresentam, se apropriam do conhecimento são diferentes. O diálogo passa a ser uma estratégia diferenciada, com possibilidades de favorecer a articulação e os currículos escolares podem ser comparados a políticas setoriais de caráter homogeneizador. Discutir suas dimensões é primar por uma investigação que possa colaborar para a edificação do perfil da escola como um espaço de cultura plural, em que os contornos de representações do mundo real sejam expressos no corpus linguístico na educação (Berger \& Luckmann, 1987); nos habitus; no capital cultural (Bourdieu, 1994) e em todos os elementos sociais que gravitam ao redor do fazer educacional e que podem explicitar políticas formuladas e executadas. Silva (2014) pontua que temas como multiculturalismo e diferenças se tornam centrais e, por isso, são dignos de discussão nas pedagogias oficiais, que ocorrem no cotidiano escolar, no chão da sala de aula. Para o autor, o "multiculturalismo" "apoia-se em um vago e benevolente apelo à tolerância e ao respeito com a diversidade e a diferença" (Silva, 2014, p. 73); e deixa transparecer que a ideia de diversidade, nessa perspectiva, é uma grande problemática, pontuando ainda que:

Na perspectiva da diversidade, a diferença e a identidade tendem a ser naturalizadas, cristalizadas, essencializadas. São tomadas como dados ou fatos da vida social diante dos quais se deve tomar uma posição. (Silva, 2014, p.73).

Visto sob esse olhar, parece fácil definir "identidade" como sendo "[...] simplesmente aquilo que se é: 'sou brasileiro', 'sou jovem', 'sou negro', 'sou heterossexual', [...]” (Idem, 
p.74). Nesse contexto, a diferença é concebida como autorreferenciada, ou seja, que remete a si própria. Porém, a diferença, assim como a identidade, se materializa, ganha existência e corpo em nossos espaços.

Diante desse contexto, Moreira \& Candau (2008) justificam e defendem a importância dos currículos multiculturalmente orientados e pontuam alguns princípios básicos para sua formulação, que deve se iniciar com a necessidade, na escola, de contextualização e processo de construção das diferenças e das desigualdades. Para os autores, diferenças e desigualdades não podem ser vistas com naturalidade, pois são construções "históricas de homens e mulheres, sendo, portanto, passíveis de serem desestabilizadas e mesmo transformadas" (p.30). O grande desafio da escola/ educação é respeitar e considerar legítimas todas as identidades.

Observando as Diretrizes Curriculares Nacionais Específicas para a Educação Básica (BRASIL/MEC/SEB, 2009), percebe-se que elas partem de uma proposta de "currículo em movimento", cujo foco visa estimular a construção de currículos mais adequados à realidade dos estabelecimentos escolares e às necessidades de todos os sujeitos envolvidos no processo educativo. Nessa mesma linha, os Parâmetros Curriculares Nacionais - PCN's (1997) apresentam uma variedade de temas transversais que devem estar vinculados aos currículos e trabalhados em sala de aula.

Moreira e Candau (2014), argumentam que tais diretrizes e documentos oficiais produzidos no âmbito do MEC, "já permitem reconhecer o espaço que se tem conferido, em políticas e revisões curriculares, às temáticas da diversidade cultural e da identidade" (Moreira \& Candau, 2014, p.47). Essa valorização se torna mais evidente tanto na última década do século XX quanto nas primeiras do século XXI.

Assim, para atender às novas demandas sociais, os cursos de Formação de professores vêm fazendo constantes ajustes em seus projetos pedagógicos. A última alteração se deu em função das Resoluções CNE. nº 02 de 2015/2019 que estabeleceu novas regras e diretrizes para a formação de professores no Brasil. As novas mudanças curriculares pré-anunciadas e em fase de implementação deverão alterar essas diretrizes, sobretudo no que diz respeito ao perfil dos egressos dos cursos de licenciatura e suas respectivas habilitações. Alguns educadores temem a extinção de algumas áreas e salientam que, caso isso ocorra, teremos juntamente com o novo currículo - a necessidade de implementação de disciplinas que permitam múltiplas habilidades nos cursos de licenciaturas.

No Estado de Goiás, a SEDUCE, a partir da formação para reorientação curricular e 
consolidação da educação contínua, vem utilizando nos últimos anos várias estratégias cuja finalidade é construir uma gestão democrática e participativa, em que haja equidade. Quando pensamos em uma educação para todos, devemos ir além do reconhecimento meramente verbal de que as exclusões ainda se fazem presentes e buscar um fortalecimento de práticas que possam materializar o que estamos chamando de "universalização" da educação.

A partir dessas premissas da "Educação para Todos" e "Universalização da Educação", temos em Cury (2005) que é na escola, mas não somente ali, que se podem desconstruir mentalidades, posturas e comportamentos que atingem a alteridade com preconceito e discriminação. Convém acrescentar que é na escola, mas não só nela, que se pode ajudar a formar crianças e jovens cuja autoestima lhes propicie o respeito por si próprios e pelos outros, condições necessárias para o cumprimento de seus deveres e para a luta por seus direitos como cidadão de nosso país e do mundo contemporâneo (Cury, 2005, Apud Moreira \& Candau, 2014, p.47).

\section{Metodologia}

A metodologia adotada pela pesquisa foi de cunho bibliográfico que é desenvolvida a partir de estudos já existentes e disponíves em livros e artigos científicos (Gil, 2008). Além disso, segundo esse autor é possível seguir um roteiro para que a pesquisa seja realizada de maneira mais eficaz, pois permite um entender e realizar a exploração das fontes bibliográficas com a leitura do material e elaboração de fichas que ajudam na organização das ideias.

Assim, a leituras dos artigos científicos, livros e de capítulos de livros possibilitaram compreender e estabelecer as categorias educação infantil e a moralidade na infância, que foram apresentadas nas seções seguintes

\section{À guisa de conclusão}

Partindo da constatação de que a sociedade está em uma intensa mudança sociocultural, oriunda da modernidade, aqui entendida como em Anthony Giddens (1991, p. 11) "estilo, costume de vida ou organização social que emergiram na Europa a partir do século XVII, e que ulteriormente se tornaram mais ou menos mundiais em sua influência”, 
podemos destacar algumas alterações nas formas de ser homem ou mulher e nos papéis por eles desempenhados nessa nova sociedade, marcada fortemente pela diversidade de identidades e múltiplas culturas. Nesse novo cenário social, urge a necessidade de (re)visitar alguns paradigmas científicos e educacionais, haja vista a crise da ciência que abre um leque de discussões e atitudes frente às diferenças. Por isso, identificar e analisar as identidades que emergem a partir das diretrizes curriculares impostas, pode colaborar em vários aspectos, dentre eles o desenvolvimento de ações contra os preconceitos, voltadas principalmente aos grupos das denominadas minorias sociais.

\section{Resultados}

Compartilhamos das concepções de Candau (2011) que a diferença situa as desigualdades existentes entre as culturas e no interior delas e apostamos nos ideais de Freire (1996) quando direciona a intencionalidade pedagógica para o contexto de educação multicultural. Frente ao exposto, afirmamos que a escola é o local, por excelência, de encontro de diferentes. É no ambiente escolar, repleto de tanta diversidade que, entretanto, podem ocorrer episódios de tolerância, respeito ao outro, empatia e superação do preconceito, como também o inverso de tudo isso.

O ideal seria que esse ambiente de diversidade a que chamamos de escola estivesse cada vez mais preparado para o acolhimento das diferenças. Assim, esperamos identificar se e como as questões ligadas a identidades e diferenças aparecem nos currículos escolares das instituições vinculadas, campo do presente estudo, bem como os discursos declarados e a realidade vivida na sala de aula.

\section{Referências}

André, M. E. D. A. (1995). Etnografia da prática escolar. Campinas: Papirus.

Berger, P. L.; Luckmann, T. (1985). A construção social da realidade: tratado de Sociologia do Conhecimento. Petrópolis, RJ: Vozes.

Bourdieu, P. (1998). Gênese e Estrutura do campo religioso. In: Bourdieu, Pierre. A economia das trocas simbólicas. São Paulo: Perspectiva, $5^{\mathrm{a}}$ ed. p.45,57; 69,78. 
(1989). O poder simbólico. Tradução de Fernando Tomaz. Rio de Janeiro: Editora Bertrand Brasil.

. (2010). A dominação masculina. Tradução Maria Helena Kunhner. 9a Ed. Rio de Janeiro: Bertrand Brasil.

Bogdan, Roberto C. \& Biklen, Sari Knopp. (1982). Investigação qualitativa em educação: uma introdução à teoria dos métodos. Boston: Allyn and Bacon.

Brasil. Conselho Nacional de Educação. Conselho Pleno. (2015). Parecer $n^{o}$ 2/2015. Diretrizes Curriculares Nacionais para a Formação Inicial e Continuada dos Profissionais do Magistério da Educação Básica. Brasília, DF: CNE.

. (1998). Constituição da República Federativa do Brasil: texto constitucional promulgado em 5 de outubro de 1988, com as alterações determinadas pelas Emendas Constitucionais de Revisão nos 1 a 6/94, pelas Emendas Constitucionais nos 1/92 a 91/2016 e pelo Decreto Legislativo no 186/2008. - Brasília: Senado Federal, Coordenação de Edições Técnicas, 2016. Disponível em: https://www2.senado.leg.br/bdsf/bitstream/handle/id/ 518231/CF88_Livro_EC91_2016.pdf . Acesso em 10.09.2017.

\section{How to cite this article (APA format):}

Purificação, Marcelo Máximo; Catarino, Elisângela Maura; Teixeira, Maria Filomena Rodrigues; Santana, Lousana de Jesus; Abdalla, Cláudia de Souza; Alves, Angélica Ferreira (2020). Curriculum and Identity its Impacts on the School Context in Goiás: Points and Counterpoints. Am. In. Mult. J., Jul to Oct. (9) 5, 196-204.

Received: 10/01/2020;

Accepted: 10/05/2020. 